\title{
From comparative effectiveness research to patient-centered outcomes research: policy history and future directions
}

\author{
Laura P. D’Arcy, Ph.D., M.P.A., and Eugene C. Rich, M.D. \\ Mathematica Policy Research, Inc., Washington, DC
}

\begin{abstract}
Containing growth in health care expenditures is considered to be essential to improving both the long-term fiscal outlook of the federal government and the future affordability of health care in the US. As health care expenditures have increased, so too have concerns about the quality of health care. Better information on the clinical effectiveness of alternative treatments and other interventions is needed to improve the quality of care and restrain growth in expenditures. This article explains the key role played by the federal government in defining the context and process of comparative effectiveness research as well as its funding. Subsequently, the article explores the mission, priorities, and research agenda of the Patient-Centered Outcomes Research Institute, which is an independent, nonprofit corporation established in 2010 by the Patient Protection and Affordable Care Act.

(http://thejns.org/doi/abs/10.3171/2012.4.FOCUS12106)
\end{abstract}

\section{KEY WORDS • comparative effectiveness research • health care costs • patient-centered outcomes research}

$\mathrm{C}$ ONTAINING growth in health care expenditures is considered to be essential to improving both the long-term fiscal outlook of the federal government and the future affordability of health care in the US. Federal expenditures for Medicare beneficiaries are predicted to increase from $\$ 520$ billion in 2010 to $\$ 970$ billion in 2021.6 More generally, concerns exist about overall growth in health care spending, since the share of gross domestic product accounted for by health care rose from $13.8 \%$ in 2000 to $17.9 \%$ in 2009 and is projected to reach nearly $20 \%$ by $2020 .{ }^{3,4}$ As health care expenditures have increased, so too have concerns about the quality of health care..$^{5,17}$ Better information on the clinical effectiveness of alternative treatments is needed to improve quality of care. ${ }^{22,30}$ Such information has substantial promise for both containing growth in health care

\footnotetext{
Abbreviations used in this paper: $\mathrm{ACA}=$ Patient Protection and Affordable Care Act; AHCPR = Agency for Health Care Policy and Research; AHRQ = Agency for Healthcare Research and Quality; $\mathrm{ARRA}=$ American Recovery and Reinvestment Act; $\mathrm{CBO}=$ Congressional Budget Office; CER = comparative effectiveness research; DHHS $=$ Department of Health and Human Services; $\mathrm{EHC}=$ Effective Health Care; FCCCER = Federal Coordinating Council for Comparative Effectiveness Research; IOM = Institute of Medicine; MMA = Medicare Prescription Drug, Improvement, and Modernization Act; NCHSR = National Center for Health Services Research; NIH = National Institutes of Health; OTA = Office of Technology Assessment; PCOR = patient-centered outcomes research; PCORI = Patient-Centered Outcomes Research Institute; PCORTF $=$ Patient-Centered Outcomes Research Trust Fund; PORT $=$ Patient Outcomes Research Team .
}

expenditures and improving quality. ${ }^{7,11,15}$ As this article explains, the federal government has played a key role in defining the context and process of comparative effectiveness research (CER) as well as its funding. After discussing historical changes in the definition and funding of CER, the article explores the mission, priorities, and research agenda of the Patient-Centered Outcomes Research Institute (PCORI), which is an independent, nonprofit corporation established in 2010 by the Patient Protection and Affordable Care Act (ACA).

\section{Evolving Conceptions of CER}

Researchers who systematically review the clinical literature have recognized for decades the need for better evidence regarding "what works best for whom" in health care, but the specific terminology regarding CER has evolved as policy makers have wrestled with how to define the appropriate role for the federal government in this effort. Key elements of CER that have changed during this debate include the range of interventions to be studied, the role of cost as an outcome measure, and the intended audience for the research findings. In 1996, an expert panel convened by the Agency for Health Care Policy and Research (AHCPR) defined CER (then called outcomes and effectiveness research) as including treatments for specific medical conditions and broader program- or system-level interventions. ${ }^{21}$ Analysis of costs linked to health-related quality of life was included as part of the definition. In its 2007 definition of CER, the Congressional Budget Office 
(CBO) included costs as a factor relevant to comparison of different interventions but took a narrow view of interventions by focusing solely on treatment for individual medical conditions. ${ }^{7}$ Both definitions indicated multiple intended audiences including clinicians and patients.

The American Recovery and Reinvestment Act (ARRA) of 2009 established the Federal Coordinating Council for Comparative Effectiveness Research (FCCCER), whose definition of CER included not just treatment but also prevention, diagnosis, and monitoring of health conditions. ${ }^{8}$ The FCCCER also identified a wider range of relevant interventions than either the AHCPR panel or the $\mathrm{CBO}$, including "medications, procedures, medical and assistive devices and technologies, diagnostic testing, behavioral change, and delivery system strategies." The definition of CER established in 2009 by the Institute of Medicine (IOM) Committee on Comparative Effectiveness Research Prioritization was very similar to that of the FCCCER. ${ }^{15}$ Definitions of CER from the FCCCER and the IOM included clinicians and patients as target audiences along with other decision makers such as purchasers and policymakers. Unlike the AHCPR panel and the CBO, neither the FCCCER nor the IOM definition included the word "cost," although the FCCCER report included cost as a measure of potential impact.

In 2010, the ACA further broadened the scope of CER to include "health care interventions, protocols for treatment, care management, and delivery, procedures, medical devices, diagnostic tools, pharmaceuticals (including drugs and biologicals), integrative health practices, and any other strategies or items being used in the treatment, management, and diagnosis of, or prevention of illness or injury in, individuals." 25 The ACA included health outcomes, clinical effectiveness, and risks and benefits as outcomes. Like the FCCCER and IOM definitions, the ACA did not mention cost. Although the ACA does not prohibit PCORI from funding studies that measure health care use or overall spending, the legislation limited analysis of costs as part of CER by prohibiting use of quality-adjusted life years by PCORI to establish recommendations of effective health care and by the Secretary of the Department of Health and Human Services (DHHS) to determine coverage, reimbursement, or incentive programs. ${ }^{27}$

A noteworthy difference in emphasis between CER as defined by CBO and the FCCCER and patient-centered outcomes research (PCOR) as defined by the PCORI is the primary audience: PCOR is primarily intended to inform individual patient decision making rather than targeting a wider range of audiences such as payers and policymakers (although both of those groups are considered stakeholders by PCORI). According to a working definition approved in March 2012 by the PCORI Board of Governors, the purpose of PCOR is to help "people and their caregivers communicate and make informed health care decisions, allowing their voices to be heard in assessing the value of health care options." ${ }^{23}$ One way that PCORI operationalizes the focus on individuals in PCOR is through examination of outcomes "that people notice and care about such as survival, function, symptoms, and health related quality of life."

\section{Federal Funding of CER}

While many private entities fund at least some CER, it has become evident that the private sector will never fund the quantity of this research needed to inform clinical decision making. ${ }^{18,21,22,29}$ High-quality CER is costly, which means that groups such as Consumer Reports that rely on patient subscriptions are unlikely to have adequate financial resources to fund a substantial amount of CER. Although drug and device manufacturers, health plans, and large employers may have sufficient financial resources to fund CER, other disincentives exist. Drug and device manufacturers face the risk that results of CER might support the use of a competitor's product rather than their own. Even if the CER sponsored by manufacturers is objective, patients may not view it as such. ${ }^{10}$ Funding substantial amounts of CER may not be justifiable for payers such as health plans and large employers because CER has 2 characteristics of a public good: 1) use of CER by its funder does not reduce its ability to be used by other entities; and 2) exclusion of one's competitors from the benefits of CER is difficult, since results are often available publicly through means of dissemination such as peer-reviewed journals. Of course, some large delivery systems could produce their own proprietary CER, but attempts to produce such exclusive "evidence" would prevent the research from being subjected to appropriate peer review as well as limit its value for contributing to future scientific developments in that clinical topic.

Because of these limitations in the potential for funding by the private sector, public sector funding is critical for CER. Federal funding began years before the term "comparative effectiveness research" was first used. One of the first federal entities to fund CER was the Office of Technology Assessment (OTA), which was established in 1972 and provided Congress with objective analysis on a wide range of topics including cost-effectiveness analyses of health care issues. Criticism that the OTA duplicated work done elsewhere in the government contributed to its closure in $1995 .^{16}$ The National Center for Health Services Research (NCHSR) was created in 1968 with goals including "devise and test advanced health care delivery concepts and systems"14 and was replaced by the Agency for Health Care Policy and Research (AHCPR) in 1989. ${ }^{13}$ Along with a larger budget came greater independence, as the AHCPR was established as a separate agency within DHHS. ${ }^{12}$ Much of the new funding for AHCPR was for research on outcomes of health care. ${ }^{12}$

One of the initiatives of the AHCPR was a set of research projects called Patient Outcomes Research Teams (PORTs). The PORTs were charged with using available data to focus on common, costly clinical conditions that had regional variation in outcomes and resource use. ${ }^{9}$ By the mid-1990s, this outcomes research had become controversial; for example, research from the low-back pain PORT and guidelines based on the PORT's work questioned the value of back surgery in several clinical situations. ${ }^{29}$ Following attacks on the AHCPR from advocacy organizations, the agency received a $21 \%$ budget cut after nearly being defunded in $1995 .{ }^{13}$ In addition to the budget cut, the AHCPR ceased development of clinical practice 


\section{Comparative effectiveness to patient-centered outcomes research}

guidelines in favor of supporting external evidence-based practice centers. ${ }^{13}$ Yet when the AHCPR was replaced by the Agency for Healthcare Research and Quality (AHRQ) in 1999, the reauthorization bill passed with a unanimous vote in the Senate and nearly unanimous vote in the House.

In 2003, the Medicare Prescription Drug, Improvement, and Modernization Act (MMA) directed the AHRQ to conduct and support research on "the outcomes, comparative clinical effectiveness, and appropriateness of heath care items and services" and "strategies for improving the efficiency and effectiveness of such programs." 19 The MMA focused on patients and providers as the users of this research by requiring that research "reflect the principle that clinicians and patients should have the best available evidence upon which to make choices ... recognizing that patient subpopulations and patient and physician preferences may vary." The Effective Health Care (EHC) Program was established by AHRQ following the MMA. Work by the EHC Program includes review and synthesis of existing scientific evidence, generation of new scientific evidence, and translation of research findings into formats for 3 audiences: patients, clinicians, and policymakers. ${ }^{1}$ Despite this new authority, however, funding appropriated to AHRQ for the EHC Program was quite modest: only $\$ 15$ million in 2007, at a time when economist Gail Wilensky was calling for a "multibilliondollar comparative effectiveness center." 32

Substantial new federal investments in CER were made through the ARRA and ACA. These investments stood in sharp contrast to past years when total federal funding for AHRQ and its predecessor agencies was no more than $1 \%$ of the budget for the NIH. ${ }^{13}$ In 2009 , ARRA provided \$1.1 billion for CER to the office of the Secretary of DHHS, NIH, and AHRQ. The IOM and the newly created FCCCER were authorized to advise the Secretary of the DHHS with developing priorities for spending the $\$ 1.1$ billion. The IOM developed a list of 100 priority topics ranked by quartiles. The FCCCER developed 4 key pillars for ARRA-funded CER investments: research, human and scientific capital for CER, CER data infrastructure, and dissemination and translation of CER. ${ }^{8}$ More than 400 CER projects were funded through ARRA in these various categories, the majority through DHHS, NIH, and AHRQ as well as some by the Centers for Medicare and Medicaid Services, FDA, and other agencies (http://gold.ahrq.gov/projectsearch/).

The ACA created PCORI and established the PatientCentered Outcomes Research Trust Fund (PCORTF) to support its mission. The PCORI's status as an independent, nonprofit corporation and the establishment of the PCORTF protects the public financial support for this activity from the political stresses of the annual congressional appropriations process. The intense battles over funding for OTA and AHCPR underscore the challenge of using the political process to secure consistent support for such high-stakes research and the significance of this unique approach to funding and directing this effort. The PCORTF received $\$ 10$ million in 2010, $\$ 50$ million in 2011, and $\$ 150$ million in 2012. Funding from 2013 through 2019 will be $\$ 150$ million per year from general revenue appropriations and additional funds from annual per capita charges from Medicare, health insurance, and self-insured plans. By 2014, total annual funding for the PCORTF will reach nearly $\$ 500$ million. ${ }^{31}$ The ACA specified that AHRQ and the office of the Secretary of DHHS annually receive $16 \%$ and $4 \%$ of the total amount appropriated to the PCORTF, respectively, for activities such as dissemination of PCORI-supported research. ${ }^{28}$

\section{Future of CER}

The PCORI is an independent, nonprofit corporation that was established by Congress through the ACA. Its purpose is to help stakeholders make informed health decisions by improving the quality and relevance of evidence about effective prevention, diagnosis, treatment, monitoring, and management of health conditions through research, evidence synthesis, and dissemination of research findings. ${ }^{26}$ The PCORI is governed by a 21-member Board of Governors that includes the directors of NIH and AHRQ as well as representatives from private and other public organizations appointed by the Government Accountability Office. ${ }^{31}$ Its mission is to help people make informed health care decisions with an ultimate goal of improving health care delivery and outcomes (http://www.pcori.org/about/mission/). The mechanism by which PCORI aims to achieve this mission is producing and promoting the use of high-integrity, evidence-based information stemming from research guided by patients, caregivers, and the broader health care community. The bulk of PCORI's funds will be used to support research, including pilot projects, research contracted by the PCORI Methodology Committee, and PCOR.

The ACA requires PCORI to identify research priorities and establish a research agenda. In response, PCORI developed 5 draft national priorities for research: comparative assessment of options for prevention, diagnosis, and treatment; improving health care systems; communication and dissemination research; addressing disparities; and accelerating PCOR and methodological research. ${ }^{24}$ To develop the proposed research agenda from the $5 \mathrm{draft}$ national priorities for research, the Board of Governors relied on the following 9 PCORI criteria listed in the ACA: impact on health of individuals and populations, improvability through research, inclusiveness of different populations, addresses current gaps in knowledge/variation in care, impact on health care system performance, potential to influence decision making, patient-centeredness, rigorous research methods, and efficient use of research resources.

The proposed initial research agenda includes multiple items for each of the national priorities for research. ${ }^{24}$ It supports specific study questions but does not identify conditions or treatments to study. Components of the research agenda related to comparative assessment of options for prevention, diagnosis, and treatment include alternative clinical options, patient differences in response to therapy, and patient preferences for various outcomes. Patients are also featured in the elements of the research agenda for each of the other 4 priorities for research; for example, improvement in shared decision making is listed as an agenda item related to communication and dissemination research. 


\section{P. D’Arcy and E. C. Rich}

The PCORI is seeking diversity in its research portfolio on several levels, including stakeholder involvement, investigators, medical conditions, and research questions. ${ }^{24}$ To that end, PCORI incorporated stakeholder input while creating the draft national priorities for research and proposed initial research agenda, and both the national priorities and research agenda were available for public comment in early 2012. The proposed initial research agenda emphasizes outcomes that are important to patients and their caregivers and is designed to promote engagement with patients and their caregivers as well as key stakeholders in implementation settings. Engagement with these groups is intended to span the spectrum of research from project design and governance to review and dissemination of findings. Researchers submitting proposals to PCORI will need to include stakeholder involvement (and in particular, patient involvement) in their proposed research to be successful in the funding process.

\section{Conclusions}

Public investment in CER is seen as a valuable enterprise by many patients, clinicians, and payers. ${ }^{20} \mathrm{~A}$ recent forum of the American Surgical Association concluded that "the processes and goals of CER are of the highest priority and remain in line with the surgeons' practice and professionalism." "2 Changes in the definition of and funding for CER in recent decades and, in particular, as part of the ACA have important implications for what type of research will be generated, how it will be conducted, and who is likely to benefit. The establishment and operation of PCORI has the potential to affect decision making by patients as well as a broad range of clinicians, and surgery is no exception. A key indicator of whether investments in CER and PCOR are producing desired results will be whether the information produced is actually helpful to physicians and patients in real-world decision making. Certainly PCORI is attempting to learn from concerns expressed during past federal efforts at CER, with its emphasis on the inclusion of patients and clinicians in developing research priorities and focus on helping patients understand how the research evidence applies to their particular circumstance.

The interest in PCOR by the academic medicine and broader research community is very high; in 2011, PCORI received 856 applications for 40 pilot project awards. However, it remains to be seen whether the enthusiasm for PCOR by policymakers and researchers will translate to increased development of truly informative research and thereby improvements in patient care.

\section{Disclosure}

The authors report no conflict of interest concerning the materials or methods used in this study or the findings specified in this paper.

Author contributions to the study and manuscript preparation include the following. Conception and design: both authors. Drafting the article: D'Arcy. Critically revising the article: Rich. Reviewed submitted version of manuscript: Rich. Approved the final version of the manuscript on behalf of all authors: D'Arcy. Study supervision: Rich.

\section{Acknowledgment}

The authors acknowledge helpful comments from Timothy Lake on an early version of this article.

\section{References}

1. Agency for Healthcare Research and Quality: What is the Effective Health Care Program. (http://www.effectivehealth care.ahrq.gov/index.cfm/what-is-the-effective-health-careprogram1/) [Accessed April 20, 2012]

2. Bland KI, Hoyt DB, Polk HC Jr, Niederhuber JE: Comparative effectiveness research: relative and efficient outcomes in surgery patients. Ann Surg 254:550-557, 2011

3. Centers for Medicare and Medicaid Services: National Health Expenditures Aggregate, Per Capita Amounts, Percent Distribution, and Average Annual Percent Change: Selected Calendar Years 1960-2010. Baltimore: Centers for Medicare and Medicaid Services, 2011 (https://www.cms.gov/ NationalHealthExpendData/downloads/tables.pdf) [Accessed April 20, 2012]

4. Centers for Medicare and Medicaid Services: National Health Expenditures Projections 2010-2020. Baltimore: Centers for Medicare and Medicaid Services, 2011 (https://www.cms. gov/NationalHealthExpendData/downloads/proj2010.pdf) [Accessed April 20, 2012]

5. Commonwealth Fund Commission on a High Performance Health System: Why Not the Best? Results from a National Scorecard on U.S. Health System Performance. New York: Commonwealth Fund, 2006 (http://www.commonwealthfund. org/Publications/Fund-Reports/2006/Sep/Why-Not-the-Best-Results-from-a-National-Scorecard-on-U-S--Health-System -Performance.aspx) [Accessed April 20, 2012]

6. Congressional Budget Office: March 2011 Medicare Baseline: By fiscal year. Washington, DC: Congressional Budget Office, 2011 (http://www.cbo.gov/sites/default/files/cbofiles/ attachments/medicare2011.pdf) [Accessed April 20, 2012]

7. Congressional Budget Office: Research on the Comparative Effectiveness of Medical Treatments: Issues and Options for an Expanded Federal Role. Washington, DC: Congressional Budget Office, 2007 (http://www.cbo.gov/sites/default/ files/cbofiles/ftpdocs/88xx/doc8891/12-18-comparativeeffec tiveness.pdf ) [Accessed April 20, 2012]

8. Federal Coordinating Council for Comparative Effectiveness Research: Report to the President and the Congress. Washington, DC: Federal Coordinating Council for Comparative Effectiveness Research, 2009 (http://www.hhs.gov/recovery/ programs/cer/cerannualrpt.pdf) [Accessed April 20, 2012]

9. Freund D, Lave J, Clancy C, Hawker G, Hasselblad V, Keller R, et al: Patient Outcomes Research Teams: contribution to outcomes and effectiveness research. Annu Rev Public Health 20:337-359, 1999

10. Garber AM: How the Patient-Centered Outcomes Research Institute can best influence real-world health care decision making. Health Aff (Millwood) 30:2243-2251, 2011

11. Garber AM, Sox HC: The role of costs in comparative effectiveness research. Health Aff (Millwood) 29:1805-1811, 2010

12. Gray BH: The legislative battle over health services research. Health Aff (Millwood) 11:38-66, 1992

13. Gray BH, Gusmano MK, Collins SR: AHCPR and the changing politics of health services research. Health Affair (Millwood) Suppl Web Exclusives:W3-283-W3-307, 2003

14. Institute of Medicine Division of Health Care Services: Health Services Research. Washington, DC: National Academies Press, 1979

15. Institute of Medicine of the National Academies, Committee on Comparative Effectiveness Research Prioritization: Initial National Priorities for Comparative Effectiveness Research. Washington, DC: National Academies Press, 2009 


\section{Comparative effectiveness to patient-centered outcomes research}

16. Leary WE: Congress's Science agency prepares to close its doors. New York Times. September 24, 1995; p 26

17. McGlynn EA, Asch SM, Adams J, Keesey J, Hicks J, DeCristofaro A, et al: The quality of health care delivered to adults in the United States. N Engl J Med 348:2635-2645, 2003

18. Medicare Payment Advisory Commission: Report to Congress: Promoting Greater Efficiency in Medicare. Washington, DC: Medicare Payment Advisory Commission, 2007 (http://www.medpac.gov/documents/jun07_entirereport.pdf) [Accessed April 20, 2012]

19. Medicare Prescription Drug, Improvement, and Modernization Act of 2003: H.R. 1 (108th). (http://www.govtrack. us/congress/bills/108/hrl) [Accessed April 20, 2012]

20. Members of the Alliance of Comparative Effectiveness Stakeholders: Testimony on Comparative Effectiveness Research: Alliance of Comparative Effectiveness Stakeholders. Agency for Healthcare Research and Quality, National Advisory Council for Healthcare Research and Quality. (http://www. ahrq.gov/about/nac/aces.htm) [Accessed April 20, 2012]

21. Mendelson DN, Goodman CS, Ahn R, Rubin RJ: Outcomes and effectiveness research in the private sector. Health Aff (Millwood) 17:75-90, 1998

22. Orszag PR, Ellis P: Addressing rising health care costs-a view from the Congressional Budget Office. N Engl J Med 357:1885-1887, 2007

23. Patient-Centered Outcomes Research Institute: Patient-Centered Outcomes Research Definition Revision: Response to Public Input. Washington, DC: Patient-Centered Outcomes Research Institute, 2012 (http://www.pcori.org/assets/ PCOR-Definition-Revised-Draft-and-Responses-to-Input. pdf) [Accessed April 20, 2012]

24. Patient-Centered Outcomes Research Institute Board of Governors: Developing PCORI's National Priorities for Research and First Research Agenda. Washington, DC: Patient-Centered Outcomes Research Institute, 2012 (http:// www.pcori.org/assets/Program-Development-CommitteeReport.pdf) [Accessed April 20, 2012]

25. Patient Protection and Affordable Care Act of 2010, Pub Law
111-148, 124 Stat. 727 (March 23, 2010) (http://www.gpo.gov/ fdsys/pkg/PLAW-111publ148/pdf/PLAW-111publ148.pdf) [Accessed April 24, 2012]

26. Patient Protection and Affordable Care Act of 2010, Pub Law 111-148, 124 Stat. 728 (March 23, 2010) (http://www.gpo.gov/ fdsys/pkg/PLAW-111publ148/pdf/PLAW-111publ148.pdf) [Accessed April 24, 2012]

27. Patient Protection and Affordable Care Act of 2010, Pub Law 111-148, 124 Stat. 741 (March 23, 2010) (http://www.gpo.gov/ fdsys/pkg/PLAW-111publ148/pdf/PLAW-111publ148.pdf) [Accessed April 24, 2012]

28. Patient Protection and Affordable Care Act of 2010, Pub Law 111-148, 124 Stat. 743 (March 23, 2010) (http://www.gpo.gov/ fdsys/pkg/PLAW-111publ148/pdf/PLAW-111publ148.pdf) [Accessed April 24, 2012]

29. Rich EC: The policy debate over public investment in comparative effectiveness research. J Gen Intern Med 24:752-757, 2009

30. Tunis SR, Benner J, McClellan M: Comparative effectiveness research: policy context, methods development and research infrastructure. Stat Med 29:1963-1976, 2010

31. Washington AE, Lipstein SH: The Patient-Centered Outcomes Research Institute-promoting better information, decisions, and health. N Engl J Med 365:e31-e33, 2011

32. Wilensky GR: Developing a center for comparative effectiveness information. Health Aff (Millwood) 25:w572-w585, 2006

Manuscript submitted March 30, 2012.

Accepted April 11, 2012.

Please include this information when citing this paper: DOI: 10.3171/2012.4.FOCUS12106.

Address correspondence to: Laura P. D’Arcy, Ph.D., M.P.A., Mathematica Policy Research, Inc., 1100 1st Street NE, 12th Floor, Washington, DC 20002-4221. email: 1darcy@mathematica-mpr. com. 